\title{
$O$ perfil do gerente de projeto de software em um ambiente de desenvolvimento fisicamente distribuído
}

\author{
Gustavo Yuji Sato¹, Elisa Hatsue Moriya Huzita², Tânia Fátima Cali Tait ${ }^{3}$ \\ Departamento de Informática - Universidade Estadual de Maringá \\ \{gsato,emhuzita, tait\}@din.uem.br
}

\begin{abstract}
Resumo: Este artigo tem como objetivo o levantamento de informações sobre o perfil do gerente de software em um ambiente de desenvolvimento fisicamente distribuído. O perfil engloba: habilidades, conhecimento e responsabilidades de um gerente de projeto de software em um projeto cujos participantes, se encontram dispersos geograficamente, em vários locais.
\end{abstract}

\section{Introdução}

O avanço das tecnologias de telecomunicações fez com que uma nova forma de desenvolvimento se tornasse possível: o desenvolvimento de projetos onde recursos, investimentos, usuários e equipe de desenvolvimento estão distribuídos em diferentes locais físicos. Trazendo benefícios como redução de custos em novas contratações de pessoal e disseminação de conhecimento por toda a organização.

Nesse cenário, temos um novo desafio. Como gerenciar um projeto nos quais recursos (humanos e materiais), stakeholders e artefatos podem se encontrar em diferentes pontos do globo terrestre? Quais são os problemas típicos na gerência de projeto de software em um ambiente de desenvolvimento fisicamente distribuído e qual é o perfil e conhecimentos necessários para que o gerente resolva esses problemas? Este projeto foca o perfil e o conhecimento do gerente de projetos e faz parte do projeto de pesquisa de Huzita (1999) e Enami (2005).

\section{Materiais e métodos}

Para definir o perfil necessário para a gerência de projetos de software em um ambiente de desenvolvimento fisicamente distribuído, foi necessário realizar uma pesquisa bibliográfica, inicialmente, a respeito projetos e gerência de projetos de forma genérica. Após isso, foi feito o levantamento de dados sobre o gerente de projetos, o perfil de um gerente de projetos: conhecimentos administrativos, técnicos, habilidades, responsabilidade, etc.

Realizou-se, também, uma pesquisa a respeito dos problemas no desenvolvimento de software e projetos distribuídos, para se traçar o perfil do gerente de projetos em um ambiente de desenvolvimento distribuído de software.

\section{Projeto}

Segundo o Project Management Institute, um projeto é o esforço temporário empreendido para criar um produto ou serviço único [PMBOK, 2004]. Ou seja, o projeto tem início e fim bem definidos e o seu resultado é a criação de um produto ou 
serviço novo. Portanto, um projeto é sempre único, embora existam projetos similares entre si e que sigam os mesmos processos.

Como projeto é o desenvolvimento de uma idéia, não se sabe o resultado final. Essa idéia pode gerar o resultado inicialmente esperado, mas também, pode se transformar durante o andamento do processo de criação; ser considerada inviável ou incoerente e ter o seu desenvolvimento abortado.

\section{O gerente de projetos e suas funções}

Num mundo globalizado e competitivo, as indústrias e empresas necessitam de constante inovação. Lançar produtos e serviços novos é essencial para manter-se a frente dos concorrentes e ganhar espaço no mercado. Entretanto, há muitos riscos envolvidos na tentativa de criar um novo produto. Ele pode ser financeiramente inviável, pode não corresponder às expectativas dos consumidores ou ter sua produção limitada devido aos fatores tecnológicos.

Para reduzir os riscos relativos a projetos é necessário um profissional competente capaz de lidar com mudanças e riscos. O gerente de projetos está presente em todas as fases do projeto (inicio planejamento, execução e controle). Ele deve assegurar que o projeto seja concluído com sucesso, dentro do tempo, custo e escopo. As funções do gerente de projetos estendem a do gerente administrativo. Henri Fayol descreve, no modelo de administração clássico, cinco funções do gerente [Cleland, 2000]: rever, organizar, coordenar, comandar, controlar.

\section{Conhecimentos do gerente de projetos}

O PMI (Project Management Institute) é uma organização sem fins lucrativos de profissionais da área de gerência de projetos. Entre as várias atividades do PMI, podem ser citados: programas educacionais, seminários e sua certificação, a PMP (Project Management Professional).

A publicação mais importante do PMI é o PMBOK (Project Management Body of Knowledge), um guia onde se descreve conhecimentos e as melhores práticas dentro da área de gerência de projetos. Além de padronizar os conceitos usados na gerência de projetos. Transcrito de uma forma genérica, o PMBOK pode ser usado em todas as áreas em que a gerência de projetos é aplicada, ou seja, tanto para construção de civil, processos industriais, desenvolvimento de software, entre outros.

O PMBOK descreve entradas, técnicas e ferramentas e saídas de 44 processos, agrupados em nove áreas de conhecimentos. São elas: gerenciamento de integração; gerenciamento de escopo; gerenciamento de tempo; gerenciamento de custos; gerenciamento de qualidade de projeto; gerenciamento de recursos humanos; gerenciamento das comunicações do projeto; gerenciamento de riscos; gerenciamento de aquisições.

\section{6. Área de aplicação do projeto}

O conhecimento necessário para a gerência de projetos pode ser estudado de uma forma genérica, abrangendo todas as áreas que a gerência de projetos é aplicada. Entretanto, os conhecimentos para a gerência de diferentes projetos variam. Um projeto possuiu um 
contexto. E é nesse contexto que a gerência é aplicada, exigindo perfis de gerentes diferentes.

Três características devem ser consideradas na alocação de um gerente a um projeto: gerenciais, administrativas e técnicas. Por exemplo, um projeto de recursos humanos exige mais capacidade administrativa, enquanto uma troca de sistema operacional exige maior técnica. Entretanto, nenhuma das três características deve tender a zero [Souza, 2003].

Embora não seja necessário que o gerente de projetos seja um especialista na área de aplicação do projeto e na tecnologia utilizada nela, ele não deve ser um leigo no assunto. É importante que esteja familiarizado com os termos usados no projeto, para a comunicação com a equipe técnica.

\section{Habilidades do gerente de projetos}

As habilidades do gerente de projetos são tão importantes para o sucesso do projeto quanto o seu conhecimento. Isso ocorre pelo fato de que a área de gerenciamento de projetos é relativamente nova em comparação a engenharia, ciências e administração. Outra razão pelas quais as habilidades têm grande peso na escolha de um gerente de projeto se deve ao fato que elas não podem ser ensinadas por meio de livros, salas de aulas comuns. Para que um indivíduo as possua, é necessário treiná-las. Entre as habilidades necessárias para um bom gerente estão: a capacidade de liderança, poder de abstração do conhecimento e habilidades de comunicação.

\subsection{A liderança}

Em tempos posteriores, para se ter controle sobre um grupo, era necessário o uso da autoridade, punições para se obter o melhor desempenho dos subordinados. Atualmente, essa filosofia não é considerada eficaz em termos de gerenciamento de projetos. Um bom líder deve ser capaz de exercer esse controle por meio do respeito, confiança e motivação.

Embora a teoria dos traços de personalidade considere a liderança uma característica natural dos indivíduos, ou seja, um líder nasce com o perfil de liderança. Corrente atuais consideram que a liderança não é nata, ela deve ser treinada [Cleland, 2000]. Um líder aprende por meio de exemplos. Para que existam futuros bons líderes, é necessário que eles aprendam com seus líderes. Por exemplo, o líder deve ser o primeiro a entrar e o último a sair, caso seja necessário realizar horas extras para alcançar o cronograma previsto no projeto, o líder deve estar presente.

\subsection{Habilidades cognitivas}

Cognição diz respeito à aquisição de conhecimento, considerada uma das habilidades mais importantes para o gerente de projetos. Aprender rapidamente é essencial já que um projeto se tratar do desenvolvimento de um novo produto, cujos resultados são incertos.

As habilidades cognitivas podem ser classificadas em seis níveis, segundo Buzin (2003): conhecimento; compreensão; aplicação; análise; síntese e avaliação. 


\subsection{Habilidades comunicação}

A comunicação é um fator decisivo para o sucesso do projeto. É através dela que é possível realizar o controle do projeto; receber resposta da equipe; integrar os diversos processos; controlar o progresso do projeto; etc., ou seja, sem a comunicação, é impossível realizar qualquer atividade em equipe.

Em uma organização, existem duas formas de comunicação: formal e informal. A comunicação formal se dá por meio de documentos, relatórios, pronunciamentos, reuniões. A gerência da comunicação se torna mais difícil pelo fato de que, além das informações formais, há a comunicação informal, verbal. As conversas no cafezinho podem trazer importantes informações sobre os problemas e dúvidas que a equipe de projeto enfrenta. Um estudo, concluiu que os gerentes organizacionais preferem a informação informal à escrita por ser mais flexível, trazer uma resposta mais rápida e serem mais flexíveis [Laudon, 1999].

\section{Aspectos relevantes para a gerência de projetos de software}

O conhecimento necessário para a administração de projetos de software consiste basicamente dos mesmos necessários ao gerenciamento de projetos definido no PMBOK. O fator que diferencia o projeto de software de demais projetos é a área de aplicação. Além dos conhecimentos administrativos, é desejável que um gerente de projetos de software tenha também alguns conhecimentos técnicos, que ajudarão na maioria das tomadas de decisão. Tais conhecimentos incluem as seguintes áreas [ESA, 1995]: métodos e ferramentas; padrões de desenvolvimento e codificação; modelo lógico; requisitos de software; modelo físico; arquitetura do projeto; detalhamento do projeto; gerenciamento de configuração; verificação e validação; garantia de qualidade.

Grandchamp (2002), ao fazer um estudo do cenário de desenvolvimento de software em grandes empresas, tecnologias adotadas, problemas enfrentados e como são solucionados, concluí que:

- Existe a comunicação direta entre gerente de desenvolvedor quando alguma decisão que interfira em seus trabalhos deve ser tomada. Durante todo o desenvolvimento, porém, o contato é maior com o cliente.

- Há uma grande preocupação no controle de custo. Seja no aprimoramento de seu software para controle de projetos, seja no uso de métricas para estimativa de custo.

- As especificações do projeto que chegam à mão dos desenvolvedores são incompletas. Os dados para o desenvolvimento não satisfazem às condições necessárias, o que faz com que novos requisitos apareçam durante o ciclo de desenvolvimento. Causando mudanças no escopo do projeto, atraso no cronograma e aumento de custo.

- A visão do gerente e desenvolvedores em relação ao atraso na entrega dos projetos é diferente. Desenvolvedores dizem que o tempo disponível para o termino do trabalho, dificilmente é suficiente. Enquanto gerentes, afirmam que não há atrasos relevantes na entrega do produto. 
- Na maioria das empresas, não há um processo bem definido para o desenvolvimento de software.

- Há carência de padrões bem definidos de metodologia para documentação, formalização e fluxo de informações.

- Não há um planejamento da estrutura analítica do projeto.

\section{Impacto do desenvolvimento distribuído em um projeto}

Em um projeto, a equipe compartilha o mesmo objetivo. Na busca desse, desenvolvedores podem ter opiniões diferentes de como será implantada a solução. O conflito também pode ser causado por dependências entre atividades. Por exemplo, na construção civil, o projeto de tubulações, adotando canos maiores ou menores, pode afetar o projeto da fiação elétrica.

A escolha da solução se dá pela forma de discussão e negociação entre os desenvolvedores, profissionais capacitados e responsáveis por seus atos. Caso não seja possível solucionar o conflito dessa maneira, ele é levado a um nível hierárquico superior, ou resolvido em uma reunião.

Em projetos cujos membros se encontram no mesmo local, a solução desses conflitos ocorre de maneira simples. As discussões entre desenvolvedores podem ocorrer de maneira informal, na mesa do café; membros da equipe podem ser convocados facilmente pra uma reunião. Entretanto, no projeto distribuído, os desenvolvedores nem sempre podem se encontrar cara a cara, diminuindo o fluxo de informação formal e informal.

Mesmo com o uso das tecnologias de telecomunicações atuais, o fluxo de informação é prejudicado. Os seguintes cenários podem ser citados com exemplo:

- Nem sempre a comunicação pode ser síncrona, já que integrantes podem trabalhar em períodos diferentes. Causando a redução de interação entre desenvolvedores.

- A equipe é formada por pessoas de países diferentes, tendo que se comunicar com uma língua na qual não tem fluência.

- Mesmo que haja fluência na língua estrangeira, é necessário conhecer os termos técnicos utilizados na outra língua.

Outros problemas também podem ser causados pela distancia geográfica entre a equipe de desenvolvimento, tal como as diferenças culturais. Olson (2002) cita alguns problemas causados por estas:

- Indivíduos de culturas diferentes são motivados de formas diferentes. Em países cujo individualismo é valorizado, pessoas são motivadas por ganhos materiais e reconhecimento. Em países onde há ênfase no coletivo, pessoas são motivadas por valores familiares e relações pessoais.

- Em muitos países, feriados são determinados pela religião e tradições. Essas podem variar, por exemplo: Natal e páscoa.

- Dias úteis variam entre os países. Em Israel, o período de trabalho vai de domingo a quinta-feira, enquanto nos Estados Unidos, de segunda a sexta. 
- Em algumas culturas, como Estados Unidos, tempo e prazos são muito importantes. Em outros, é comum haver uma longa discussão, não importando o tempo, até que o assunto seja concluído.

- Culturas diferentes negociam de forma diferente. Em algumas, acordos são realizados com um aperto de mão, outras são requerem contratos. Nos Estados unidos, acordos são discutidos publicamente, enquanto no Japão, são discutidos pessoalmente e reuniões são realizadas para cerimônias de assinatura de contrato.

- As diferenças entre classes sociais. Na China e Rússia, classe e hierarquia são importantes, enquanto em países como Estados Unidos e Alemanha, a hierarquia é menos significante. As expectativas de quando o gerente espera que seus subordinados discutam são diferentes.

\section{Resultado e discussão}

A partir dos dados coletados, podem-se levantar pontos nos qual o gerente de projetos de software, em um ambiente de projetos distribuídos, deve ter maior enfoque para que o projeto tenha maiores chance de atingir o sucesso. São eles: comunicação, conhecimento do gerente. A partir desses pontos, pode-se chegar ao perfil do gerente de projetos.

\subsection{Comunicação}

Fica claro que esse é um fator crítico na gerência de projetos distribuídos, não apenas de software, mas de maneira geral, é a comunicação. Segundo ESA (1995), a dispersão geográfica resulta em uma pobre comunicação, para melhorar a comunicação o gerente de projetos deve re-alocar a equipe em um local próximo sempre que possível. Entretanto, isso não é o objetivo do ambiente de desenvolvimento distribuído.

No planejamento de comunicações, o gerente deve levar em conta a distribuição geográfica na analise de requisitos de comunicação, para que os processos de distribuição de informações, relatórios de desempenho e gerenciamento de partes interessadas sejam realizados de forma eficaz. É importante o investimento em ferramentas de comunicação, como: teleconferência; troca de mensagens; groupware e percepção, ferramentas que focam o desenvolvimento de trabalhos em grupo e a visão do grupo sobre o trabalho de que cada indivíduo desenvolve.

Deve haver maior enfoque no levantamento de requisitos e especificação do projeto, já que a troca de informações estará debilitada. A maioria dos desenvolvedores não terá contato direto com o cliente. Questões que podem ser resolvidas informalmente no projeto de software, não são dão da mesma forma no projeto distribuído. É necessário que haja maior compromisso com a documentação formal.

\subsection{Conhecimento do gerente}

Quanto aos conhecimentos do gerente de projetos, concluí-se que o conhecimento necessário para gerenciar o projeto de software se trata do conjunto de conhecimento a cerca de processos administrativos em gerência de software com adição conhecimentos técnicos para o desenvolvimento de software. Em especial, a aplicação de métricas de 
software, já que há um interesse na área em detectar inicialmente o tempo e os recursos que o projeto consumirá.

Deve ser adotada a criação da estrutura analítica do projeto, decomposição do projeto em partes cujo gerenciamento é mais fácil, além de facilitar o uso de métricas e desenvolvimento do cronograma. O projeto é dividido em entregas necessárias para o projeto seja concluído. Entrega é qualquer produto, resultado ou capacidade para realizar um serviço exclusivo e verificável na documentação do plano de gerenciamento do projeto, e que devem ser produzidos e fornecidos para terminar o projeto [PMBOK, 2004]. Elas podem ser formadas por outras entregas ou pacotes de trabalhos. O pacote de trabalho é o nível mais baixo da EAP, eles são facilmente gerenciáveis e custos e cronogramas podem ser estimados de forma mais confiável [PMBOK, 2004]. Critérios sugeridos pela ESA (1995) para a criação de pacotes de trabalhos, podem reduzir o número de conflitos dentro de um projeto, são eles:

- Coerência - as tarefas dentro de um pacote de trabalho devem ter o mesmo objetivo;

- Ligação - as dependências entre os pacotes de trabalho devem ser minimizadas, assim os membros da equipe podem trabalhar independentemente;

- Continuidade - a produção dos pacotes de trabalho deve ser de tempo integral para maximizar a eficiência.

\subsection{Aspectos culturais}

Quanto aos aspectos culturais, não há uma forma simples de identificá-los. Eles estão ocultos em todas as ações que tomamos. As pessoas não pensam em si tendo valores ou cultura, elas simplesmente imaginam que os valores que trazem consigo, são os que importam a toda humanidade [Olson, 2004]. O gerente não pode tomar sua cultura como padrão ou certa. Não apenas por parte do gerente, mas de todos os participantes, deve haver a consciência de que povos diferentes possuem culturas diferentes.

\section{Conclusões}

Com relação ao perfil do gerente de projetos, a comunicação é uma parte essencial para o sucesso do projeto. O afastamento geográfico entre os participantes traz perdas na troca de informações de modo informal, principal meio de comunicação no desenvolvimento de software. Faz-se necessário que o gerente de projetos de software tenha o perfil adequado para desenvolver bem as atividades no contexto do ambiente distribuído. Características como: facilidade de comunicação; habilidades para resolução de conflitos e conhecimentos em processos de gerenciamento de comunicação e coordenação se tornam fundamentais para esse tipo de ambiente.

Também, fica claro que para gerentes que possuem apenas a experiência de desenvolvimento de forma local, ao adotar projetos em ambiente distribuído, é necessário o maior investimento em tecnologia; processos de desenvolvimento e documentação mais bem definidos do que os atuais adotados por empresas de desenvolvimento de software para que o impacto sobre a comunicação entre participantes seja absorvido para adotar o desenvolvimento de software em um ambiente distribuído. 
No trabalho de Grandchamp (2002), nota-se que no cenário atual, aos gerentes, faltam conhecimento sobre questões administrativas e possuem maior enfoque técnico no projeto. Gerentes cuja origem na organização se dá por meio de promoção de desenvolvedores devem realizar treinamento e cursos de atualização em gerencia de projetos. Bem como, gerentes que não possuem conhecimento técnico, devem fazer cursos e treinamentos sobre desenvolvimento de software.

Em um ambiente distribuído, características como habilidade para planejar e gerenciar processos de comunicação, bem como o conhecimento necessário para realizá-los, é essencial para um bom gerente de projetos. Como trabalho futuro, é sugerido, o levantamento de aspectos pertinentes à comunicação formal e processos de comunicação, em um ambiente distribuído, no qual, entre alguns tópicos sugeridos: documentação de código (como javadoc), documentação de projeto e domínio do projeto, requisitos do software, processo de comunicação de duvidas entre desenvolvedores, processo de comunicação cliente-equipe, etc.

\section{Referências}

Cleland, David I.; Ireland, Lewis R. (2000). "Gerência de projetos”, edited by Reichmann \& Affonso Editores.

PMBOK, (2004) "Um guia do conjunto de conhecimentos de projetos" $3^{\circ}$ Edição, edited by Projetct Management Institute.

Laudon, Kenneth C.; Laudon, Jane P. “Sistemas de infomação”, 4 Edição, 1999.

Souza, Eduardo J.A. (2003) “GERÊNCIA DE PROJETOS” http://www.pmirs.org/PMIRSJournal/PMI-RSJournalNro04.pdf março/2006.

Buzin, Paulo F. W. Keglevich de (2003). "O perfil do gerente de projeto que faz a diferença”, http://www.pmirs.org/PMI-RSJournal/PMI-RSJournalNro05.pdf março/2006.

Grandchamp, Régis Eduardo. (2002) “Gerenciamento de projetos de software”

European Space Agency (ESA) (1995). Guide to software project management. Edited by The Netherlands: ESA Publications Division.

Karatmaa, Arno (2000), “Coordination in Distributed Product Development Teams”,

Olson, Judith; Olson, Olson, Gary M. (2004), “Culture surprises in software develpment teams" 